\title{
Impacto da produção de olerícolas em sistema de base agroecológica na qualidade
}

\section{química do solo}

\author{
Impact of vegetable production in an agroecological based system on the chemical quality of the soil \\ Impacto de la producción de hortalizas en un sistema de base agroecológica en la calidad química \\ del suelo
}

Recebido: 01/01/2022 | Revisado: 05/01/2022 | Aceito: 08/01/2022 | Publicado: 12/01/2022

Cleiton Jardel Carneiro

ORCID: https://orcid.org/0000-0001-5606-0932 Universidade Regional do Noroeste do Estado do Rio Grande do Sul, Brasil E-mail: cleiton.carneiro@sou.unijui.edu.br

Darlan Ariel Prochnow

ORCID: https://orcid.org/0000-0003-3699-074X Universidade Regional do Noroeste do Estado do Rio Grande do Sul, Brasil E-mail: darlan.prochnow@ sou.unijui.edu.br

Nelson José Thesing

ORCID: https://orcid.org/0000-0001-7123-0717 Universidade Regional do Noroeste do Estado do Rio Grande do Sul, Brasil E-mail: nelson.thesing@unijui.edu.br

Tatiane Peno Nogueira

ORCID: https://orcid.org/0000-0001-7414-7943 Universidade Regional do Noroeste do Estado do Rio Grande do Sul, Brasil

E-mail: tatipeno@gmail.com

Luíza Motta Klockner

ORCID: https://orcid.org/0000-0001-8807-380X Universidade Regional do Noroeste do Estado do Rio Grande do Sul, Brasil E-mail: luiza.klockner@sou.unijui.edu.br

\begin{abstract}
Resumo
O estudo buscou analisar de forma comparativa duas análises de solo, uma amostra de solo de uma gleba que encontra-se em sistema produtivo de hortaliças, com base agroecológica não certificada, em exploração há aproximadamente 4 anos, e a outra amostra de solo da mesma gleba porém na forma de testemunha contendo apenas uma correção de solo com calcário calcítico. Foram analisados os aspectos físicos e químicos através de análise de solo. Os dados foram catalogados, analisados e comparados. Baseou-se a evolução dos níveis químicos da análise de solo com a análise do composto orgânico utilizado na forma de adubação. Identificou-se que houve elevação em quase todos os macros e micronutrientes presentes na análise, com destaque para fósforo e potássio. Apenas um micronutriente manganês apresentou diminuição no índice disponível no solo.
\end{abstract}

Palavras-chave: Agricultura familiar; Agroecologia; Solos.

\begin{abstract}
The study sought to comparatively analyze two soil analyzes, a soil sample from a plot of land that is in a vegetable production system, with a non-certified agroecological base, in operation for approximately 4 years, and the other soil sample from the same glebe but in the form of a control containing only a soil correction with calcite limestone. Physical and chemical aspects were analyzed through soil analysis. The data were cataloged, analyzed and compared. The evolution of the chemical levels of the soil analysis was based on the analysis of the organic com-post used in the form of fertilization. It was identified that there is an increase in al-most all macro and micronutrients present in the analysis, with emphasis on phosphorus and potassium. Only one micronutrient, manganese, showed a decrease in the index available in the soil.
\end{abstract}

Keywords: Family farming; Agroecology; Soils.

\section{Resumen}

El estudio buscó analizar comparativamente dos análisis de suelo, una muestra de suelo de una parcela que se encuentra en un sistema de producción vegetal, con base agroecológica no certificada, en exploración por aproximadamente 4 años, y otra muestra de suelo de la misma gleba pero en forma de un control que contiene solo una corrección del suelo con caliza calcítica. Los aspectos físicos y químicos se analizaron mediante análisis de suelos. Los datos fueron catalogados, analizados y comparados. La evolución de los niveles químicos del análisis del suelo se basó en el análisis del compost orgánico utilizado en forma de fertilización. Se identificó que hubo un 
aumento en casi todos los macro y micronutrientes presentes en el análisis, especialmente fósforo y potasio. Solo un micronutriente de manganeso mostró una disminución en el contenido disponible en el suelo.

Palabras clave: Agricultura familiar; Agroecología; Suelos.

\section{Introdução}

A agricultura familiar tem grande importância na matriz produtiva nacional e principalmente no que se refere a produção de alimentos, segundo Mattei (2014). Do ponto de vista produtivo destaca-se a grande importância da agricultura familiar, com ênfase nas seguintes informações: $87 \%$ da produção total de mandioca; $70 \%$ da produção de feijão; $46 \%$ da produção de milho; $34 \%$ da produção de arroz; $38 \%$ da produção de café; e 58\% da produção de leite. Além disso, os dados revelam que 59\% do plantel de suínos; 50\% do plantel de aves; e 30\% do plantel de bovinos são de responsabilidade da agricultura familiar. Esses números comprovam a grande capacidade de produção de alimentos que a agricultura familiar possui e a relativa importância no cenário nacional.

Quando se refere a questão econômica, Mattei (2014) destaca que: em termos das receitas, o IBGE divulgou que 1/3 delas provinha da agricultura familiar. Porém, quando se considera o valor total da produção dos estabelecimentos agropecuários do país, observa-se que a agricultura familiar respondia em 2006 por quase $40 \%$ do valor total. Esses dados evidenciam a capacidade de agregação de valor à produção e a diversificação produtiva que a agricultura familiar proporciona, além da capacidade de maior agregação de valor por área utilizada e maior empregabilidade no meio rural.

Tendo em mente a fundamental importância da agricultura familiar na produção de alimentos, entende-se que para se ter produção satisfatória é necessário preservar as características químicas do solo visando melhorar a qualidade do mesmo e incrementar a produção. Deste modo, a agroecologia se apresenta como meio de sustentabilidade para os cultivos da agricultura familiar. Para Severino (2011) a agroecologia é uma ciência responsável por agregar conhecimentos de diversas ciências, como as ciências agrárias, exatas e humanas, além de saberes populares e tradicionais.

Segundo Milindro et. al (2016) a avaliação dos atributos químicos de um solo a partir de amostras representativas torna-se necessária quando se deseja conhecer e identificar a real condição dos constituintes químicos da fertilidade presente em uma área, sendo capaz de orientar sobre as condições e o potencial dos solos para a agricultura. Desta forma o presente estudo busca realizar uma análise comparativa entre duas amostras de solo pertencentes à mesma gleba, sendo as amostras denominadas de amostra 1 e amostra 2, onde, amostra 1 corresponde a uma área que não possui produção de hortaliças tendo recebido apenas uma aplicação de calcário calcítico. Já a amostra 2 corresponde a área de produção de hortaliças que se encontra em manejo de base agroecológica a aproximadamente 4 anos.

Deste modo, o estudo tem por objetivo analisar a evolução do solo em manejo de base agroecológica, na produção de olerícolas no município de Coronel Bicaco-RS. Dentro deste, busca verificar se houve melhoria ou não na qualidade do solo explorado; busca ainda analisar os padrões físicos e químicos do solo; além de desenvolver histórico de utilização de insumos na área pesquisada.

\section{A Produção Agroecológica e sua Relação com a Agricultura Familiar}

O solo é de longe um dos agentes de maior importância no desenvolvimento das plantas sejam elas de interesse econômico ou não, segundo Primavesi, 2002. Necessitamos que o solo apresente as seguintes características: permita um bom desenvolvimento da raiz; tenha o suficiente em nutrientes para a planta; conserve a maior quantidade de água disponível à planta; seja suficientemente arejado; não contenha substâncias tóxicas, prejudiciais à raiz. A olericultura é uma atividade produtiva que provoca uma rápida degradação do solo, quando esta atividade não é desenvolvida pensando na manutenção dos aspectos de qualidade e sanidade do solo esta degradação se acelera ainda mais e em poucos anos torna-se inviável 
economicamente a produção ou quando viável o número e o volume de utilização de pesticidas e adubação se eleva desordenadamente. Ainda segundo Primavesi, 2002: A sanidade vegetal, de um ou outro modo está ligada à "sanidade" do solo. Em solo decadente é difícil criar cultura sadia.

Uma das maneiras de agregar produtividade é o uso de adubos químicos e agrotóxicos. No Brasil, o consumo de agrotóxicos cresceu muito nas últimas décadas, transformando o país em um dos líderes mundiais no consumo de agrotóxicos (Faria et al., 2007; Soares, 2010; Brasil, 2013a). Mesmo assim, o uso destes produtos não condiz com uma agricultura sustentável, que alie retorno econômico com preservação ambiental. Por isso, a alternativa de sustentabilidade para a agricultura são as práticas agroecológicas.

A agroecologia nasce como uma alternativa na busca pelas condições que visam a manutenção da atividade e do grupo social através de um projeto de desenvolvimento sustentável (Caporal et al., 2009; Lopes, 2014).A forma de produção agroecológica parte da premissa de manutenção e ou melhoria das condições do solo, tendo como base para isso o uso de materiais naturais e fontes orgânicas de nutrientes, sabe-se que um dos principais constituintes do solo são rochas decompostas ao longo de milhares de anos, desta forma algumas alternativas para a recuperação do solo e melhoria da qualidade do mesmo, parte da premissa de reativação da capacidade natural do solo, através por exemplo de compostos de rochas, que buscam em síntese rejuvenescer o solo, fornecendo através destes compostos, material mineral para decomposição e posterior disponibilização destes minerais ao solo, para serem aproveitados pelas plantas.

Os principais efeitos dos fertilizantes orgânicos sobre as propriedades químicas do solo são: enriquecimento gradual do solo com macro e micronutrientes essenciais às plantas e o aumento gradativo do teor de matéria orgânica do solo (Trani, et. al., 2013). O mesmo autor destaca ainda que: os principais efeitos dos adubos orgânicos sobre as propriedades físico-químicas do solo são: melhoria na adsorção de nutrientes, que é a retenção físico-química de cátions, diminuindo, em consequência, a lixiviação de nutrientes causada pela chuva ou pela irrigação; a) aumento gradativo da capacidade de troca de cátions (CTC ou T) do solo, melhorando indiretamente sua fertilidade.

A adubação sob o paradigma orgânico pressupõe que a fertilidade do solo deve ser mantida ou melhorada, utilizandose recursos naturais e das atividades biológicas. Na medida do possível, devem-se utilizar recursos locais, bem como subprodutos orgânicos que proporcionem o fornecimento de nutrientes, de forma ampla e diversificada, devendo priorizar a ciclagem de nutrientes por meio de restos culturais, compostos e resíduos orgânicos e adubações verdes com leguminosas ou plantas espontâneas.

Portanto, as práticas agroecológicas contribuem para a permanência das famílias de agricultores no campo, pois valorizam os saberes locais, proporcionam o manejo sustentável dos solos e a manutenção dos recursos naturais (Guedes \& Martins, 2011). Na medida do possível a agricultura de base agroecológica busca trabalhar com a redução de custo de produção, partindo da premissa de que a mesma é praticada em sua maioria por estabelecimentos da agricultura familiar, observa-se que a escala de produção é menor e o volume produzido também, consequentemente a receita bruta destes estabelecimentos é em volume menor que em sistemas extensivos de produção olerícola.

A importância da Agricultura Familiar sustenta-se nos seguintes aspectos: (a) está intrinsecamente vinculada à segurança alimentar e nutricional; (b) Preserva os alimentos tradicionais, além de contribuir para uma alimentação balanceada e salvaguardar a agrobiodiversidade e o uso sustentável dos recursos naturais; (c) representa uma oportunidade para impulsionar as economias locais, especialmente quando combinada com políticas específicas destinadas a promover a autonomia do agricultor, reafirmando sua identidade, a proteção social e o bem-estar das comunidades e o desenvolvimento rural sustentável; e d) demonstra o potencial para geração de postos de ocupação econômica (Embrapa, 2014, p. 4). 
A redução de custos com insumos vem a calhar e apresenta-se mais viável que a produção em sistema químico, não descarta-se o uso de tecnologias mais avançadas, as quais apresentam resultados mais efetivo e consequentemente elevam o custo de produção, dentre estas tecnologias podemos citar o uso da biomineralização de solos através dos compostos de rochas e o uso de agentes biológicos de combate a pragas e doenças.

Uma alternativa altamente viável e que vem de encontro com uma das premissas da agroecologia são os consórcios produtivos e a rotação de culturas. O sistema consorciado é empregado, sobretudo, pelos pequenos agricultores, que dessa forma, procuram aproveitar ao máximo as áreas limitadas de que dispõem, dos insumos e da mão-de-obra utilizada em capinas, adubações, aplicações de defensivos e outros tratos culturais (Caetano et al., 1999). Observa-se que os consórcios produtivos reduzem os riscos relacionados a doenças e pragas, além de aumentar a renda por área, a diversificação de culturas também é uma forma de aumentar a renda final da propriedade, tendo em vista que para a produção familiar é um tanto quanto complexo manter altas escalas produtivas e analisando a forma de comercialização da produção, verifica-se que a diversificação produtiva é altamente viável para as familiar e para o ecossistema produtivo.

\subsection{Aspectos físicos, químicos e biológicos do solo}

A microbiota do solo é a principal responsável pela decomposição dos resíduos orgânicos, pela ciclagem de nutrientes e pelo fluxo de energia no solo, podendo ter influência tanto na transformação da matéria orgânica, quanto na estocagem do carbono e nutrientes minerais. Na agricultura de base agroecológica os aspectos físicos, químicos e biológicos do solo são de extrema importância, pois segue-se a premissa de que o cuidado deve estar direcionado ao solo e então a planta retirar do solo o que ela necessita para seu desenvolvimento (Cunha et al., 2012).

A produção de base agroecológica busca constantemente melhorar a atividade microbiológica do solo através do fornecimento de matéria orgânica (alimento) para os micro-organismo presentes no mesmo, efetuando assim o ciclo da reciclagem de nutrientes e tornando os mesmos disponíveis às plantas, esta forma de agricultura busca garantir ao máximo as formas de interação e relação entre microrganismos, solo e planta. Para que esta relação se estabeleça da melhor forma possível é necessário que o agricultor tenha alguns cuidados relacionados ao manejo da área de produção, como por exemplo a presença de palhada e cobertura no solo, a rotação de culturas é outro manejo de fundamental importância para manutenção da qualidade do solo e do sistema produtivo como um todo (Cunha et al., 2012). De modo geral, a qualidade do solo depende da sua composição natural, sendo também fortemente relacionada com as práticas intervencionistas do homem (Araújo et al., 2012).

Referente aos aspectos físicos do solo é necessário observar as características de cada solo, seja ele de aspecto argiloso ou com maior propensão a arenoso, os aspectos físicos do solo determinam a forma e a qualidade do desenvolvimento das culturas através de seu sistema radicular, observa-se que solos compactados problematizam o desenvolvimento das plantas e no outro oposto solos sem capacidade de agregação facilitam a lixiviação dos nutrientes, a olericultura enfrenta o problema do excesso de incisões mecânicas no solo, através do alto volume de preparação do solo o que facilita a desagregação e a destruição da estrutura dos solos.

Segundo Sediyama et.al (2014) as práticas de manejo do solo são as principais alterações nos agroecossistemas. Nessa concepção, o ambiente físico-químico tem sido apontado como o principal regulador da produção das lavouras, tanto pelas modificações físicas causadas pelo preparo e manejo do solo e, ou, pela irrigação, quanto pelas modificações químicas, com a adição de nutrientes por meio dos fertilizantes. 


\section{Metodologia}

A estratégia utilizada para a pesquisa é o estudo de caso, o qual tratou de analisar a realidade de uma área de produção específica. Para Yin (2001, p. 32) o estudo de caso "é uma investigação empírica que investiga um fenômeno contemporâneo dentro de seu contexto da vida real, especialmente quando os limites entre o fenômeno e o contexto não estão claramente definidos". De acordo com Minayo (2014), o estudo de caso contribui na compreensão do fenômeno que não está claramente definido. No caso em específico trata-se da avaliação e mensuração da evolução e ou regressão da área de produção sob manejo de base agroecológica.

Desta forma, o presente estudo apresenta-se com abordagem qualiquantitativa. Para Creswell (2010 p. 39) "os dados qualitativos e quantitativos podem ser unidos em um grande banco de dados ou os resultados usados lado a lado para reforçar um ao outro". No presente estudo, a interpretação das análises de solo, em conjunto com a observação das características de desenvolvimento das culturas, proporciona agregação de qualidade na interpretação dos aspectos relacionados à qualidade do solo.

Por fim, a pesquisa percorre o método da teoria fundamentada em dados, por tratar-se da interpretação e mensuração de análises de solo. Segundo Cassiani et.al (1996). Trata-se do modo de construir indutivamente uma teoria assentada nos dados, através da análise qualitativa destes e que, agregada ou relacionada a outras teorias, poderá acrescentar ou trazer novos conhecimentos à área do fenômeno.

\section{Resultados e Discussão}

Este trabalho busca analisar a evolução de uma área de produção de hortaliças no município de Coronel Bicaco - RS, que executa o manejo de base agroecológica há aproximadamente 4 anos com início da produção no ano de 2017. O trabalho consiste na coleta de duas amostras de solo uma amostra na área de produção e a outra em uma área pertencente à mesma gleba, porém em estágio inicial de produção, com objetivo de efetuar a comparação entre os indicativos físicos e químicos das duas amostra e identificar a evolução e/ou regressão da área ocupada pela olericultura. Observa-se que a produção desta unidade é diversificada dentro das espécies olerícolas de importância econômica na propriedade, sendo algumas delas: alface, repolho, brócolis, couve-flor, couve folha, salsa e cebolinha de tempero, chicória, almeirão e couve chinesa. Assim, buscou-se encontrar relativa diferenciação na comparação entre as duas amostras, outros indicativos foram analisados como a presença de matéria orgânica e o desenvolvimento radicular das culturas implantadas no sistema.

Em virtude de não ser possível realizar análise microbiológica na amostra de solo, a análise foi realizada de forma visual dos aspectos sanitários das culturas implantadas. Após a análise efetuou-se a catalogação dos dados obtidos o que permitiu desenvolver o comparativo entre as amostras, além disso desenvolveu-se um histórico da área de produção com insumos utilizados na recuperação do solo, para justificar as alterações sofridas na gleba analisada.

A área utilizada com olericultura sofreu inicialmente o processo de correção de solo com aplicação de calcário calcítico, posteriormente a mesma área recebeu a aplicação de farinha de rocha com a finalidade de fornecer minerais ao solo e buscar o rejuvenescimento do mesmo. Após o manejo inicial de correção de solo a área recebeu adubação orgânica na forma de esterco bovino e composto orgânico.

Os cultivos se deram de forma sucessiva e ininterruptos no período de aproximadamente 4 anos, sendo que antes do plantio de cada cultura é realizada na área o preparo do solo com subsolagem, adição de composto orgânico e confecção dos canteiros com enxada rotativa. O composto orgânico é fornecido por uma empresa especializada na produção do mesmo, o qual apresenta como ingredientes principais: cama de aviário, esterco suíno, cinza e casca de ovos. E apresenta os valores nutricionais descritos no Quadro 1. 
Research, Society and Development, v. 11, n. 1, e47211125283, 2022

(CC BY 4.0) | ISSN 2525-3409 | DOI: http://dx.doi.org/10.33448/rsd-v11i1.25283

Quadro 1: Análise química do composto orgânico.

\begin{tabular}{|l|l|}
\hline \multicolumn{2}{|c|}{ ANÁLISE QUÍMICA DO COMPOSTO ORGÂNICO } \\
\hline ITEM & VALOR \\
\hline PH & 7.9 \\
\hline Nitrogênio & $2.89 \%$ \\
\hline Fósforo & $2.03 \%$ \\
\hline Potássio & $4.30 \%$ \\
\hline Cálcio & $6.33 \%$ \\
\hline Magnésio & $1.36 \%$ \\
\hline Carbono orgânico & $23.16 \%$ \\
\hline
\end{tabular}

Fonte: Dados da pesquisa (2021).

Durante o período de produção utilizou-se apenas este insumo como adubação, também não fora utilizado adubação química ou outras fontes de nutrientes que não fosse o composto orgânico ou esterco bovino. O manejo sanitário das culturas é realizado através de pulverizações com defensivos biológicos, como extrato pirolenhoso, Trichoderma Harzianum, Bacillus Turingiensis, Beauveria bassiana, dentre outros produtos como sulfato de cobre e demais caldas de preparo artesanal.

A seguir apresenta-se os resultados obtidos através das análises de solo realizadas na área de produção e em uma área pertencente à mesma gleba, porém que não recebeu nenhuma aplicação de adubação. Observa-se que a amostra 1 corresponde a área onde não foi utilizado composto orgânico e a amostra 2 corresponde a área que se encontra a aproximadamente 4 anos em manejo com adição de composto orgânico. O Quadro 2 apresenta o comparativo entre as amostras. 
Quadro 2: Comparativo de análise química do solo.

\begin{tabular}{|l|l|l|l|l|}
\hline \multicolumn{5}{|c}{ COMPARATIVO DE ANÁLISE QUÍMICA DO SOLO } \\
\hline ITEM & AMOSTRA 1 & CLAS. & AMOSTRA 2 & CLAS. \\
\hline PH & 6,1 & & 7,2 & \\
\hline Argila & $60 \%$ & C2 & $46.0 \%$ & C2 \\
\hline CTC pH 7 & $21.3 \mathrm{cmolc} / \mathrm{L}$ & Alto & $21.6 \mathrm{cmolc} / \mathrm{L}$ & Alto \\
\hline Matéria Orgânica & $3.3 \%$ & Médio & $3.6 \%$ & Médio \\
\hline Fósforo & $7.9 \mathrm{mg} / \mathrm{L}$ & Baixo & $205.5 \mathrm{mg} / \mathrm{L}$ & M. alto \\
\hline Potássio & $601.5 \mathrm{mg} / \mathrm{L}$ & M. alto & $1715.0 \mathrm{mg} / \mathrm{L}$ & M. alto \\
\hline Cálcio & $13.8 \mathrm{cmolc} / \mathrm{L}$ & Alto & $11.4 \mathrm{cmolc} / \mathrm{L}$ & Alto \\
\hline Magnésio & $2.9 \mathrm{cmolc} / \mathrm{L}$ & Alto & $4.4 \mathrm{cmolc} / \mathrm{L}$ & Alto \\
\hline Enxofre & $18.7 \mathrm{mg} / \mathrm{L}$ & Alto & $24.8 \mathrm{mg} / \mathrm{L}$ & Alto \\
\hline Zinco & $10.4 \mathrm{mg} / \mathrm{L}$ & Alto & $56.5 \mathrm{mg} / \mathrm{L}$ & Alto \\
\hline Cobre & $11.6 \mathrm{mg} / \mathrm{L}$ & Alto & $3.3 \mathrm{mg} / \mathrm{L}$ & Alto \\
\hline Boro & $0.65 \mathrm{mg} / \mathrm{L}$ & Alto & $1.50 \mathrm{mg} / \mathrm{L}$ & Alto \\
\hline Manganês & $25.0 \mathrm{mg} / \mathrm{L}$ & Alto & $1.0 \mathrm{mg} / \mathrm{L}$ & Baixo \\
\hline
\end{tabular}

Fonte: Dados da pesquisa (2021).

Através do comparativo é possível observar uma diferenciação bastante expressiva em relação ao pH das duas áreas, vale salientar que a área denominada amostra 1, recebeu uma correção de solo com aplicação de calcário calcítico, o que justifica o valor expresso de $\mathrm{PH}$ 6.1, sendo que o $\mathrm{pH}$ base dos solos da região oscila na casa de 5.5, já a amostra 2 apresenta ph 7.2 o que se justifica ao elevado ph que o composto orgânico utilizado apresenta, na casa de 7.9.

Foi possível observar através da análise de solo que os níveis de fósforo e potássio da amostra 2 apresentam-se com valores bastante elevados, dando ênfase a esses dois nutrientes destaca-se a grande diferença que se apresenta entre as análises, no caso do potássio a concentração saiu de $601.5 \mathrm{mg} / 1$ na amostra 1 para $1715 \mathrm{mg} / 1$ na amostra 2, concentração bastante elevada o que justifica-se pelo fornecimento desse nutriente através do composto orgânico. No caso do fósforo nutriente também fornecido em boa concentração pelo composto orgânico, a concentração saiu de $7.9 \mathrm{mg} / \mathrm{l}$ na amostra 1 para $205.5 \mathrm{mg} / \mathrm{l}$ na amostra 2. Observa-se ainda que os níveis de cálcio, magnésio, enxofre, zinco, cobre e boro apresentam-se elevados na amostra 2 o que se justifica através do uso do composto orgânico e adição de esterco bovino.

Um elemento em particular apresentou valor menor na amostra 2 em relação a amostra 1, é o caso do manganês que diminuiu consideravelmente a sua concentração no solo saindo de $25 \mathrm{mg} / \mathrm{l}$ na amostra 1 que corresponde ao solo inicial antes do cultivo de hortaliça, para $1 \mathrm{mg} / 1$ na amostra 2 que corresponde a área de produção de hortaliças, estima-se que essa diferença justifique-se pelo consumo das plantas e por uma possível ausência ou disponibilidade em menor volume deste nutriente no composto orgânico, em virtude da análise do composto orgânico não contemplar os micronutrientes, fica impossível expressar uma conclusão precisa referente a este micronutriente. 
O nível de matéria orgânica oscilou pouco entre as duas amostras, com valor de 3.3\% na amostra 1 e de $3.6 \%$ na amostra 2. Vale salientar que na área de produção é efetuada a remoção dos restos culturais ao final de cada ciclo produtivo, a fim de evitar a proliferação de pragas e doenças, o manejo de cobertura do solo também não é realizado, esses dois fatores combinados afetam a disponibilidade de matéria orgânica no solo, entende-se que este ponto precisa ser reavaliado e melhorado dentro da propriedade, tendo em vista o papel fundamental da matéria orgânica na área de produção. O Quadro 3 apresenta o comparativo de análise física do solo.

Quadro 3: Comparativo de análise física do solo.

\begin{tabular}{|l|l|l|l|l|}
\hline \multicolumn{5}{|c|}{ COMPARATIVO DE ANÁLISE FÍSICA DO SOLO } \\
\cline { 1 - 2 } ITEM & AMOSTRA 1 & CLAS. & AMOSTRA 2 & CLAS. \\
\cline { 1 - 2 } Areia & $10.9 \%$ & Solo Tipo 3 & $13.5 \%$ & \multirow{2}{*}{ Solo Tipo 3 } \\
\cline { 1 - 2 } Silte & $19.5 \%$ & & $22.9 \%$ & \\
\cline { 1 - 2 } Argila & $69.6 \%$ & & $63.6 \%$ & \\
\hline
\end{tabular}

Fonte: Dados da pesquisa (2021).

Em relação à análise física do solo constata-se que o solo apresenta elevado teor de argila configurando assim solo do tipo 3, solo argiloso. Observa-se que as variações ocorridas entre as amostras são normais dentro do mesmo tipo de solo. Classifica-se o mesmo como latossolo, por apresentar coloração avermelhada, ser argiloso e apresentar textura em formato de grãos.

Referente à análise biológica do solo, não foi possível desenvolver análise laboratorial, porém é possível avaliar e descrever aspectos visuais presentes no solo, como a presença de minhocas e demais organismos presentes no solo visíveis a olho nu, como é o caso de goros e outros insetos, além da alta visibilidade das galerias produzidas pelos mesmos nos canteiros, além da sanidade das plantas que apresentou melhora constante no decorrer dos anos de exploração, de forma que a aplicação de produtos de caráter curativo diminuiu gradativamente, sendo utilizado insumos de controle preventivo.

\section{Considerações Finais}

O desenvolvimento da pesquisa tornou visível a agregação dos índices de nutrientes presentes no solo através da utilização do composto orgânico, tornou-se de grande importância a visualização da capacidade de manutenção dos valores de nutrientes mesmo sobre a produção de olerícolas que utilizam elevados volumes nutricionais para seu desenvolvimento, outro fator agravante ao esgotamento do solo é a velocidade de produção das olerícolas e o elevado volume de produção retirado anualmente da mesma área de terra.

A pesquisa comprovou que a utilização de adubação orgânica de boa qualidade é capaz de suprir em maioria a necessidade das plantas e gerar acúmulo de nutrientes nos solo, observa-se casos de deficiência nutricional específica de alguns elementos, como no caso estudado o manganês, porém considera-se em termos gerais que a adução de base agroecológica é altamente viável a produção de olerícolas.

Outro ponto a ser observado é o PH do solo que fora totalmente recuperado através do composto orgânico, é possível observar na análise química do composto o ph elevado que o mesmo possui, este fator contribui na recuperação do solo, de modo que fica comprovado através das análises, que não há necessidade de incremento de calcário e ou de farinha de rocha na 
área denominada amostra 2, apenas o micronutriente manganês deve ser incrementado na área de produção, a partir da pesquisa será analisado a melhor forma de suprir a deficiência desse elemento.

Referente a qualidade do solo é possível observar nas plantas a boa formação dos frutos e rápido crescimento, além da boa sanidade apresentada pelas culturas o que reduz drasticamente a necessidade de utilização de insumos mesmo que sejam de natureza biológica. Esse fator contribui positivamente na redução de custos com a produção das olerícolas em geral.

Estudos futuros podem analisar a composição do solo em cultivos agroecológicos e tradicionais, de forma a enaltecer ou refutar as vantagens do cultivo agroecológico. Do mesmo modo, novos estudos podem analisar as vantagens do sistema de plantio direto em áreas de cultivo agroecológico ou tradicional.

\section{Referências}

Araújo, E., Ker, J., Neves, J., \& Lani, J. (2012). Qualidade do solo: conceitos, indicadores e avaliação. Applied Research \& Agrotechnology, 5(1), 187-206.

Brasil. (2013a). Secretaria de Vigilância em Saúde - Ministério da Saúde. Boletim epidemiológico, 44 (17). http://portalarquivos2.saude.gov.br/images/pdf/2014/junho/11/BE-2013-44--17Agrot--xicos.pdf>.

Caetano, L. C. S., Ferreira, J. M., Araújo, M. L. de. (2006). Produtividade de cenoura e alface em sistema de consorciação. Horticultura Brasileira, Brasília. 17(2), 143-6. Apud: Montezano, Eduardo Matos, Peil, Roberta Marins Nogueira. Sistemas de consórcio na produção de hortaliças. Current Agricultural Science and Technology. 12(2).

Caporal, F. R., Costabeber, J. A., \& Paulus, G. (2009). Agroecologia: uma ciência do campo da complexidade. MDS/Embrapa.

Cassiani, Silvia Helena De Bortoli, Caliri, Maria Helena Larcher, Pelá, Nilza Teresa Rotter. (1996). A teoria fundamentada nos dados como abordagem da pesquisa interpretativa. Revista latino-americana de enfermagem, 4(3).

Creswell, John W. (2010). Projeto de pesquisa: métodos qualitativos, quantitativos e mistos. Artmed.

Cunha, E. Q.; Stone, L. F.; Ferreira, E. P. B.; Didonet, E. D.; Moreira, J. A. A. (2012). Atributos físicos, químicos e biológicos de solo sob produção orgânica impactados por sistema de cultivo. Revista Brasileira de Engenharia Agrícola e Ambiental, 16.

Embrapa. (2014). Visão 2014-2034: o futuro do desenvolvimento tecnológico da agricultura brasileira: síntese. Empresa de Pesquisa Agropecuária (Embrapa). https://ainfo.cnptia.embrapa.br/digital/bitstream/item/103222/1/Visao-2014-2034-O-Futuro-de-Desenvolvimento-Tecnologico-da-Agricultura-Brasileirasintese.pdf.

Faria, N. M. X., Fassa, A. G., \& Facchini, L. A. (2007). Intoxicação por agrotóxicos no Brasil: os sistemas oficiais de informação e desafios para realização de estudos epidemiológicos. Ciência \& Saúde Coletiva, 12 (1): 25-38.

Guedes, Z. M., \& Martins, J. C. V. (2011). Agroecologia e Gênero: Perspectiva Socioambiental no Assentamento Mulunguzinho em Mossoró-RN. Revista Verde, 5: 66-76.

Lopes, P. R. (2014). A biodiversidade como fator preponderante para a produção agrícola em agroecossistemas cafeeiros sombreados no Pontal do Paranapanema. Tese de Doutorado em Ecologia Aplicada - Interunidades - Escola Superior de Agricultura "Luiz de Queiroz", Piracicaba, p.172.

Mattei, L. (2014). O papel e a importância da agricultura familiar no desenvolvimento rural brasileiro contemporâneo. Rev. Econ. NE, 45, 83-91.

Milindro, Idomar Fernandes et al. (2016). Atributos químicos como indicadores de qualidade do solo sob manejo agroecológico. Cadernos de Agroecologia, $10(3)$.

Minayo, Maria Cecília de Souza. (2014). O desafio do conhecimento. (14a ed.), HUCITEC.

Primavesi, Ana. (2002). Manejo ecológico do solo: a agricultura em regiões tropicais. Nobel.

Sediyama, M. A. N.; Santos. I. C.; \& Lima. P. C. (2014). Cultivo de hortaliças no sistema orgânico. Rev. Ceres, Viçosa, v. 61, Suplemento.

Severino, L. F. (2011). Biodiversidade e Agricultura Familiar. http://blogdorancho.com/2010/06/16/biodiversidade-e-agricultura-familiar/>

Soares, W. L. (2010). Ministério da saúde. Fundação Oswaldo Cruz, http://bvssp.icict.fiocruz.br/.

Traini, P. E. et al. (2013). Adubação orgânica de hortaliças e frutíferas. IAC.

Yin, R. K. (2001). Estudo de caso: planejamento e métodos. (2a ed.), Bookman. 